\title{
EL LÈXIC CATALÀ DEL SEGLE XIX: ELS HISPANISMES DEL LABÈRNIA
}

\author{
THE CATALAN LEXICON IN THE XIX CENTURY: \\ THE HISPANISMS IN THE LABËRNIA DICTIONARY
}

\author{
Gabriel Bibiloni \\ Universitat de les Illes Balears \\ gabriel.bibiloni@uib.cat
}

Resum: Aquest article es proposa d'inventariar i analitzar els hispanismes registrats en el diccionari Labèrnia que posteriorment foren exclosos del català normatiu codificat per Pompeu Fabra. Considerant que el diccionari de Labèrnia és el més important dels que es feren abans de l'esmentada codificació i que fou el diccionari de referència de la societat culta catalana del segle xix, l'anàlisi d'aquests hispanismes ens permet d'entendre les concepcions del lèxic català que tenia aquella societat i el canvi revolucionari que representa l'acció codificadora i depuradora de Fabra.

Paraules clau: català, interferència, hispanisme, codificació, Pompeu Fabra.

Abstract: The purpose of this article is to make the inventory and analysis of the hispanisms incorporated in the dictionary of Pere Labernia which were later excluded of the standard Catalan codified by Pompeu Fabra. Considering that the Labernia dictionary is the most important of those made before the referred codification and that it was the dictionary of reference for the educated Catalan society of the XIX century, the analysis of these hispanisms allows us to understand the conception about the Catalan lexicon in that society and the revolutionary change that the codifying action of Pompeu Fabra represents.

Key words: Catalan, interference, hispanism, codification, Pompeu Fabra. 
GABRIEL BibiLONI

El lèxic català del segle XIX: els hispanismes del Labèrnia

El Diccionari de la llengua catalana ab la correspondencia castellana y llatina, de Pere Labèrnia, és considerat el millor diccionari català del segle xIx, tot i que la seva qualitat és molt lluny de la dels diccionaris actuals. A diferència de la major part de peces de la lexicografia catalana d'aquell segle i dels precedents, no havia estat escrit per a ensenyar el llatí o l'espanyol, sinó per a ser instrument de fixació i regulació del català. Per aquest fet i per la seva relativa qualitat fou obra de referència per als escriptors i la societat catalana culta del segle XIx. En aquest article posarem la nostra atenció en el tractament que aquest diccionari cabdal fa dels hispanismes. ${ }^{1}$ Aquests són generalment acceptats i incorporats a l'obra, en tant que considerats com a elements normals d'un conjunt lèxic constituït per tot allò que, d'una manera general, la gent diu i escriu. El coneixement rigorós del fenomen de la interferència lèxica no s'iniciaria fins a la centúria següent. Per això el Labèrnia és una plasmació del lèxic català usat en la llengua culta del segle Xix. I la comparació d'aquest lèxic amb el que sorgí de la codificació fabriana permet de copsar la magnitud i el caràcter revolucionari de l'obra del genial lingüista codificador del català modern.

\section{L'AUTOR}

Nascut a Traiguera (Baix Camp) el I802, Pere Labèrnia i Esteller passà la major part de la vida al Principat. Estudià al seminari de Tortosa i després al de Barcelona. En aquest fou professor d'humanitats a partir de I828. A vint anys, aproximadament, començà a sentir inquietuds per les llengües $i$ es posà a fer recerca estudiant les principals obres gramaticals i lexicogràfiques catalanes, espanyoles i llatines. El I836 fou nomenat membre de l'Acadèmia de Bones Lletres de Barcelona, que li auspicià el diccionari. A més d'aquest, publicà la versió inversa, Diccionario de la lengua castellana con las correspondencias catalana y latina (I844-48, amb dues noves edicions entre I86I i 1867), Ortografía de la lengua castellana (1849) i Gramática latina (1852). Deixà també alguns treballs inèdits, com Observaciones acerca del estilo y diversos géneros y también sobre el lenguaje trópico y figurado, el seu discurs d'ingrés a l'Acadèmia. Morí a Barcelona el I860.

I. Fem servir en aquest treball el terme hispanisme i no el més habitual castellanisme, per coherència amb el nom que donam a la llengua d'on procedeixen els manlleus (espanyol) i per coherència amb l'ús internacional, en què es fa servir el terme hispanisme. El mateix Diccionari general de la llengua catalana de l'Institut d'Estudis Catalans defineix hispanisme com a «I Idiotisme particular de la llengua castellana 2. Mot o gir d'aquesta llengua usat en una altra llengua». 


\section{EL CONTEXT}

La cultura a Catalunya en els segles XVIII i XIx està marcada per una institució cabdal com és la Reial Acadèmia de Bones Lletres de Barcelona. Fou creada el 1729, sense nom, en certa manera com a continuació de l'Acadèmia dels Desconfiats (I700I7I4), desapareguda per la seva adhesió a Carles d'Àustria. El I752 es convertí en reial i adoptà el nom definitiu, després d'aconseguir la protecció de Ferran VI, no exempta de dificultats. Acollí els més eminents intel.lectuals de l'època i tingué per vocació principal la d'estudiar exhaustivament i rigorosament la història de Catalunya.

Tanmateix, el referent de la Reial Acadèmia Espanyola, i el més remot de l'Acadèmia Francesa, estigueren presents en tot moment en els promotors i els acadèmics de la catalana. El Diccionario de autoridades (I726-1739), la primera gran realització de la institució espanyola, havia de despertar en els acadèmics catalans el desig d'emprendre una obra de les mateixes característiques. Amb tot, cal no perdre de vista el context català, marcat per la política uniformitzadora dels Borbons i el fet que la intel-lectualitat catalana majorment s'adhereix al projecte de l'Estat liberal modern, l'element vertebrador del qual, o el més important, serà l'espanyol com a llengua nacional. No havent-hi un projecte de construir una llengua nacional catalana, la tasca acadèmica respecte de la llengua hauria de ser força diferent. L'Acadèmia tingué l'espanyol com a llengua de treball i alhora impulsà una certa regularització del català, tot i que les intencions no passaven de conservar una llengua per a funcions marcadament subalternes. Malgrat tot, l'Acadèmia va fer una funció reguladora del català, treballant per a la fixació de l'ortografia, la gramàtica i el lèxic, i fou el punt de partida d'un model de llengua divuitesc que, precisament, ha estat anomenat català acadèmic (Segarra 1985).

El I769, el mateix any de la promulgació de la cèdula de Carles III impositiva de l'espanyol a l'ensenyament, el bisbe de Barcelona, el valencià Josep Climent (I706-178I) encarregà a l'Acadèmia de Bones Lletres — l'única institució que podia fer-ho- la redacció d'un diccionari català-castellà-llatí, però, tot havent-hi una intenció de recollir el lèxic antic per a explicar-lo, la finalitat principal era la difusió de l'espanyol, tasca a la qual es dedicà Climent sense dubtar (Colón-Soberanas 1986: 127).

El diccionari auspiciat pel bisbe Climent no arribà a bon port, ni tampoc altres projectes de diccionari, com el de Fèlix de Prats, baró de Sarraí, o el de Josep de Vega, tots dos concebuts per a conservar el coneixement d'una llengua antiga vista com un tresor amagat, si bé també es parla de "purificar» el català del dia. Però aquest fracàs es compensà amb el fet que, en una esfera més privada, la feina intensa de l'eclesiàstic $\mathrm{i}$ acadèmic Fèlix Amat (1750-I824), d'arreplega de materials lexicogràfics en documents 
GABRIEL BibiLONI

El lèxic català del segle XIX: els hispanismes del Labèrnia

antics, es materialitzà en el Diccionario catalán-castellano-latino (I803-1805), editat pels també acadèmics Josep Belvitges, Joaquim Esteve i Antoni Juglà.

Superant de molt els dos diccionaris principals del segle Xvir, el de Pere Torra (I640) i el de Joan Lacavalleria (I696), que tenien per objecte l'ensenyament del llatí, el de Fèlix Amat és el primer diccionari que aspira a recollir tot el lèxic català i amb definicions escaients (Colón-Soberanas 1986: I43). És un diccionari descriptiu de la llengua contemporània, amb la incorporació de mots de la llengua antiga i amb el propòsit complementari — inevitable en el seu context— de facilitar les equivalències en espanyol. El diccionari de la pre-Renaixença, com ha estat anomenat.

\section{EL DICCIONARI LABÈRNIA}

Segons diu l'autor en el pròleg $\mathrm{i}$ en la dedicatòria que fa a la Reial Acadèmia de Bones Lletres, hi començà a treballar quan tenia I8 anys (I820 o I82I) i l'acabà el I839, després de dedicar-hi divuit anys de feina.

Tal com diu també el mateix Labèrnia, les fonts en què treballà són la versió catalana de Gabriel Busa del Dictionarium latinum-hispanum et hispanum-latinum, el Thesaurus puerilis d'Onofre Pou (I575), el Dictionarium seu thesaurus catalano-latinus verborum ac phrasium de Pere Torra (1640), el Gazophylacium catalano-latinum de Joan Lacavalleria (1696), el Diccionario catalán-castellano-latino de Josep Belvitges, Joaquim Esteve i Antoni Juglà (I803-I805) i el diccionari en dos volums (acabat el I8I8) que deixà inèdit el franciscà Albert Vidal.

Segons s'afirma en el pròleg, l'obra pretén fixar «la pura y genuina ortografia y pronunciació de l'idioma catalá», un idioma que, segons Labèrnia, es trobava en un lamentable estat d' «abjecció y descuyt», davant el qual ell vol treballar per a recuperar el seu antic prestigi i esplendor. Això no lleva que el lexicògraf declari obertament la seva adhesió a l'espanyol, qualificada com a «llengua nacional» que «tan ventatjosament se ha generalisat entre nosaltres des de que formam part de la gran familia espanyola». És, doncs, una obra reguladora però alhora és un reflex del català culte escrit en el seu temps.

El diccionari de Labèrnia s’imprimí el I839 (el primer volum) i el I840 (el segon volum), a l'Estampa dels Hereus de la Vda. Pla, a Barcelona. Una segona edició, ja difunt l'autor, es publicà per Espasa Germans Editors els anys 1864-1865. Aquesta edició, sobre la qual hem treballat per a aquest article, portava a la portada l'afegit "considerablement aumentat y corretgit per una societat de literats, cultivadors de la llengua catalana», encapçalada per Robert Robert. Aquesta societat hi introduí 
l'ortografia d'Antoni de Bofarull i Adolf Blanch (Bofarull I864; Bofarull-Blanch I867), la més prestigiosa i la més seguida per la societat catalana culta abans de les normes ortogràfiques de 19I3. Encara se'n féu una tercera edició els anys I888-I892, per Espasa i Companyia, Editors, il-lustrada per Apel-les Mestres i augmentada per una Societat de Literats Catalans sota la direcció d'Ignasi Ferrer i Carrió. I, tot i ja no figurar-hi el nom de Labèrnia, el diccionari fou reeditat diverses vegades per l'editorial Salvat, fins al 1936, amb els noms de Diccionari de la llengua catalana ab la correspondencia castellana i, aprovadal'ortografia de l'Institut d'Estudis Catalans, Diccionari enciclopèdic de la llengua catalana amb la correspondència castellana.

La versió inversa —el diccionari espanyol-català- fou publicada els anys I844 $\mathrm{i}$ I848 (primer i segon volum, respectivament), amb el nom de Diccionario de la lengua castellana con las correspondencias catalana y latina (Josep Maria de Grau, impressor). Se’n va fer una altra edició els anys I86I i 1867, i encara una altra, amb el títol Novísimo diccionario de la lengua castellana con la correspondencia catalana (germans Espasa, 1866-67), amb retocs fets per Una Societat Literària.

Tot aquest seguit d'edicions mostren el bon acolliment que va tenir el diccionari de Labèrnia, que va ser el diccionari de referència i pràcticament l'únic que gaudí de prestigi i autoritat fins a la publicació del diccionari de Pompeu Fabra (Colón-Soberanas 1986: I53). És, doncs, una peça fonamental per a la conformació del català culte del segle XIX.

\section{EL CONEIXEMENT I LA CONSCIÈNCIA DE LA INTERFERÈNCIA DE L'ESPANYOL}

Un dels capítols interessants i encara per explorar a fons -malgrat aportacions importants com les de Solà (1977) i Colón-Soberanas (1986) — és la consciència de la interferència de l'espanyol sobre el català que tenien els nostres avantpassats entre els segles XVI i XIX, segles en què es produí més o menys intensament aquesta interferència. Per a iniciar aquesta aproximació al tema podríem mirar l'ús de les paraules barbarisme i castellanisme durant els segles esmentats. Barbarisme és un mot antic, documentat per primera vegada en català, segons Coromines (DECat, s. v. bàrbar) en el Torsimany de Lluís d'Averçó (final del segle XIV). I fou usat regularment a través del temps, però cal dir que amb un significat de «vici en el parlar», sense que aquest vici hagi de consistir necessàriament en un fet d'interferència. «Vici en lo parlar» és la definició que en dóna Lacavalleria (Lacavalleria I696), la mateixa definició («vici en el parlar») que es troba en el diccionari de Fèlix Amat (Belvitges, Esteve i Juglà I803- 
Gabriel Bibiloni

El lèxic català del segle XIX: els hispanismes del Labèrnia

I805). El nostre Labèrnia defineix el mot com a «vici contra la puresa del llenguatge», sense que tampoc resti clar què cal entendre per tal puresa.

D'altra banda, castellanisme és una paraula força moderna. Cercant la primera documentació en el DECat de Coromines, ens hem trobat amb el fet sorprenent que tal paraula no figura en el monumental diccionari, igual que tampoc no hi hem trobat el substantiu castellà, nom usual de la llengua espanyola. En el Corpus Textual Informatitzat de la Llengua Catalana, la primera documentació és de 1883 i correspon a un text d'Antoni de Bofarull. Al diccionari de Labèrnia no hi apareix, doncs, l'entrada castellanisme, encara que sí les entrades castellanada (definida, curiosament, com a «'acció de parlar mal lo castellá») i castellanisar («Fér castellana alguna cosa ó que semble castellana; y així dihém: ¿no sé perque s’han de castellanisar los noms catalans?»). Més avall continuarem amb la visió de la interferència de Labèrnia.

Les Regles d'esquivar vocables o mots grossers o pagesivols, de Bernat Fenollar i Jeroni Pau, carreguen contra un gran nombre de «barbarismes», consistents en arcaismes, neologismes, vulgarismes i dialectalismes — segons el punt de vista dels autors-, però no estrangerismes, cosa comprensible si tenim en compte que en el moment en què foren escrites (I487) no havia començat de manera intensa la interferència de l'espanyol. Les obres lexicogràfiques del segle XVI — Pou (I575) — i del XVII —Font (I637), Torra (I640) i Lacavalleria (I696) —, essent obres destinades a l'ensenyament del llatí, òbviament tampoc no presten gaire atenció al fenomen de la interferència de la llengua veïna.

Josep Ullastra (1690-1762) a la seva Grammática catalana embellida ab dos orthographias (1743) dedica un capítol als «Vicis que s’han d'evitár per a pronunciár i escríurer perfetamént la Llengua Cathalana». Per a Ullastre, el concepte de barbarisme s'identifica també com a vici de llengua en general, i considera com a tals barbarismes coses com fer els plurals femenins en -es (dones, cases), usar l'auxiliar ésser en lloc de haver, fer la concordança del participi (han portada la carta), el perfet perifràstic, les partícules pre-nominatives en i na i alguns altres fenòmens. Però també és barbarisme —i ara això és d'interès per al nostre propòsit— l'ús d'un mot estranger, com quitar en lloc de llevar, tret del cas en què manqui una paraula equivalent en català, cosa que ocorre, segons ell, pel que fa a paraules com luego i pues (Solà 1977: 2I).

Carles Ros (I703-1773), notari valencià afeccionat a la lexicografia, és el primer, que sapiguem, a fer unallista d'hispanismes. Al Diccionario valenciano-castellano (I764) aporta, en la nota XXV (pàgines 333 i 334), una petita llista de 42 hispanismes, la major part veritables hispanismes, però amb alguna confusió, com la de considerar incorrectes desde o novela, que proposa de substituir per dende i rondalla. D'altra banda, proposa de substituir alivio per allivi, espuela per espola i rodeo per rodeu. El I77I Ros publicà 
Correccion de vozes y phrases que el vulgo, u comun, de Valencia, ùsa, ó ha introducido, hablando (ú querièndo hablàr) en su Matèrno Idiòma (València: Francisco Burguete, editor), en què aporta 23 pàgines d'hispanismes en la mateixa línia que la llista del diccionari. Segons Solà (1977: 22), Ros obre la tradició dels «descastellanitzadors a ultrança», que cataloguen com a hispanismes els cultismes que, òbviament, tenen la mateixa forma que els equivalents espanyols (anual, comestible, navegar, en el lloc dels quals proposa anyal, menjatiu o naujar).

El I8I2 el frare mínim mallorquí Antoni Maria Servera publicà una Nueva ortografia, que du com a apèndix un diccionari d' «alguns termes españols mallorquinisats, molt útil a sa juvintud, qui desitja parlar ab hermosura y energia. Entre aquests hi ha vers hispanismes, com aliento, aliño, asco, bolsillo, càlido, cariño, halago, etc., però també paraules catalanes considerades "termes espanyols mallorquinitzats», com adversidad, apacibble, bèl-lic o pussil-làmine [sic]. Les mateixes confusions que hem vist en Carles Ros i que seran arrossegades fins a Pompeu Fabra.

A la Gramática y apología de la llengua cathalana (I815), Josep Pau Ballot (I747I82I) continua amb la concepció tradicional del barbarisme, que es comet «quant se falta a la proprietat». Una concepció més basada en el rebuig del canvi i l'aplicació d'una lògica particular que relacionada amb fenòmens d'interferència. Per a Ballot, són barbarismes nascut per nat, sigut per estat, despús ahir per antes d'ahir o ja vinc (quan criden algú) per ja hi vaig (!).

En definitiva, abans de Labèrnia hi ha entre els gramàtics i lexicògrafs, manifestada més entre els segons, una idea molt vaga de la interferència lingüística. Se sap que en el lèxic usual dels catalans hi ha paraules agafades de l'espanyol, però només una petita part és correctament identificada. Fins que els coneixements de gramàtica històrica i de lingüística comparada no assoleixin un cert nivell aquestes mancances no seran esmenades.

\section{ELS HISPANISMES DEL LABÈRNIA}

Essent clarament millor lexicògraf que tots els precedents, Labèrnia també devia tenir una comprensió de la interferència tan deficitària com es pot esperar del context vuitcentista que aquí ha estat descrit. Ell recull el lèxic que la gent diu i escriu, el qual no havia passat per cap procés de depuració, que ningú no havia estat ni era capaç de fer. En tot el diccionari només hem trobat una referència a la interferència espanyola: a l'entrada làtigo diu que «és veu castellana y massa usada en català, però sense ninguna necessitat. FUET». Una observació semblant no es fa de cap altra paraula 
Gabriel Bibiloni

El lèxic català del segle XIX: els hispanismes del Labèrnia

en tota l'obra. Amb tot, seria d'interès escatir quins hispanismes registrats en obres precedents foren rebutjats per Labèrnia, en el cas que n'hi hagi; una tasca, tanmateix, que supera el propòsit d'un article com aquest.

Lobjecte d'aquest article és identificar, llistar i analitzar els hispanismes recollits en el diccionari Labèrnia que posteriorment han estat exclosos de la llengua estàndard i que el consens general considera hispanismes rebutjables. No ens ocuparem dels hispanismes del Labèrnia que no foren impugnats a la codificació lèxica fabriana - ja sigui perquè no foren identificats o perquè hom pensà que no era procedent de depurar-los- que avui són d'ús general i segurament més nombrosos que els hispanismes del Labèrnia avui rebutjats. Els hispanismes objecte del nostre treball formen la suma de I.I50. Com dèiem al començament, aquesta nòmina dels hispanismes del Labèrnia ens permetrà de conèixer millor el català parlat i escrit en els temps precedents a la reforma fabriana.

Els hispanismes que analitzarem seran distribuïts en dos grups: A) Hispanismes amb un lexema espanyol (normalment inexistent a les altres llengües romàniques no ibèriques) que avui tothom reconeix com a hispanismes fora de la normativa (v. gr. abultar, despedir, loco, tonteria). Incloem també en aquesta llista aquelles paraules formades amb un lexema existent en català però que han estat substituïdes per paraules amb altres lexemes (v. gr. barco, gasto). B) Els hispanismes de forma, és a dir, paraules amb lexema existent en el comú de les llengües romàniques, o d'un àmbit més extens, però que tenen una forma mediatitzada per l'espanyol.

\section{A. LEXEMES ESPANYOLS}

Distingirem aquelles entrades que simplement són definides i aquelles que remeten a una altra forma (normalment genuïna). No resta clar si aquesta remissió implica una simple preferència per la forma definida o pot arribar a representar un rebuig de la forma de l'entrada sense definició. I encara hi afegirem una taula amb entrades genuïnes que remeten a una altra paraula (normalment hispanisme), segurament perquè l'autor devia considerar les primeres com a antigues o inusuals. Les indicacions entre claudàtors són nostres. 


\section{Entrades amb definició}

\section{Taula I}

abajejo
abarcar
abonar [adobar terres]
abono
abultar
acerca
aconteiximent
acossar
acreedor
adoléixer
agasajo
ahogo
ahondar
aislar
alabar
alborot
alborotar
alcansar
alentar
alevós
alevosia
aliviar
alivio
alocar (-se)
alocat
alomenos
amancebar
amanéixer
amontonar
aniquilar
antoix
anyadir
anyadit -da
apaciguar
aparato
apearse
apegar
apego
apellido
apetéixer
aplassar

aplauso
apodar
aposento
apoyar (-se)
apoyo
apreci
apremi
apremiar
apressurar
apretar
apreto
apuro
apurar
arminyo
arraygar [vegeu la taula
$\quad$ següent]
arraygo
arreglo
arremétrer
arrepentirse
arrojar
arrojat
arropar
asco
asquerós
assear
asseat
assento
assomar
assombrar
assueto
assustar
atascar
atavio
atolondrar
atolondrat
atrás
atrassos
auto [terme de dret]
averiguar
avispar

avispat

barco

barriguera

barullo

bellaco

bitxo [insecte]

bobo

bocadillo [eina de vidrier]

bodega [celler]

bodegó

borratxo [n. a. per Fabra]

botiquí

botxorn

bresso [bruc]

brillo

brio

Bruno [nom d'home]

bullici

bulliciós

bulto

buytre

cabo

calderilla

caldo [n. a. per Fabra]

candelabro

candelero

cange [de poders o presoners]

cangear

cargar

carinyo

casquillo

catarata [cascada i cataracta]

catarro

cecadero [peça del carro, esp. cejadero]

cercá -ana

cercania

cerda [cerra] v. taula 3

cernícalo

cisto [estepa]

clero [n. a. per Fabra] 
Gabriel Bibiloni

El lèxic català del segle XIX: els hispanismes del Labèrnia

\begin{tabular}{|c|c|c|}
\hline codillo & desenfado & flasco \\
\hline colmo & desfatxatés despediment & flato \\
\hline columpi & despedir & fosso \\
\hline comedir-se & desperdici & fulano \\
\hline comedit & desperdeciar & galgo \\
\hline compinxe & detrás & ganso $-\mathrm{a}$ \\
\hline contento & ditxa & garbo \\
\hline contrafallo & ditxós -a & garbós \\
\hline contrafosso & dondo [follet] & garrotillo \\
\hline contrarecibo & embustero & gasto \\
\hline contrasello & empenyar & gatillo \\
\hline cortar [interrompre una con- & empenyo & golosina \\
\hline versa] & empleo & grangear \\
\hline cortarse [quedar sense paraula] & empolvar & grifo ['griu'] \\
\hline coto & empotrar & guapo [n. a. per Fabra] \\
\hline cotxino & enclench & hermós \\
\hline croto $[$ ocell] & enfado & hermosura \\
\hline crusero & enganyabobos & hetxura \\
\hline cucaratxa & engorro & hidalgo \\
\hline cuclillas (en) & engorrós & hidalguia \\
\hline cuerdo & enredo & jalego [«justillo, armilla sense \\
\hline cundir & enserrar [tancar] & mánegas»] \\
\hline cuneta [n. a. per Fabra] & enterar & júbilo \\
\hline curro [afectat en el gust] & enterat & látigo \\
\hline cuydado & entibiar & lelo \\
\hline cuydar [n. a. per Fabra] & entiqüela & limosna \\
\hline dádiva & entoldar & limpiesa \\
\hline dato & entregar [n. a. per Fabra] & límpio -a \\
\hline deber [obligació: «complir son & escamotejar & lindo -a \\
\hline deber»] & escamotetj & lograr \\
\hline decoro & escalabre y escalabro & logro \\
\hline derramar & esmero & luego \\
\hline derretir & estrago & llamada [terme militar] \\
\hline desahogo & estribillo & llano -a \\
\hline desaliento & estribo & llisonja \\
\hline desalinyar & estropejar & llisongear \\
\hline desapegar & estropici & llisonger $-\mathrm{a}$ \\
\hline desapego & evento & llomillo \\
\hline desatino & facundo & mal-lograr \\
\hline desauciar & fallo & mal-lograt \\
\hline descabellar & fardo & mamarratxo \\
\hline descabellat & fealdat & mando \\
\hline descalabrar & fetxa [«Data de la escriptura & manguito \\
\hline descalabro & ó carta»] & marxitar \\
\hline descaro & fetxoria & marxitat \\
\hline desditxat & fiero & matxo [n. a. per Fabra] \\
\hline desempenyo & finiquito & mengano \\
\hline
\end{tabular}




\begin{tabular}{|c|c|c|}
\hline mengua & recreo & terco $-\mathrm{a}$ \\
\hline menos & reemplasso & terremoto \\
\hline menoscabar & remendo & tiesso $-\mathrm{a}$ \\
\hline menoscabo & reparo & tinglado \\
\hline modorro & repent o repente & tino \\
\hline monyo & repentí & tocay o tocayo \\
\hline $\operatorname{motxo}-\mathrm{a}$ & repuesto & tocino ['porc'] \\
\hline navio & résio -a & toldo \\
\hline nero & resquici & tontada \\
\hline novillo & ressabi & tontejar \\
\hline óbice & retrás & tonteria \\
\hline ohído & retrassar & tonto $-\mathrm{a}$ \\
\hline ornato & retruécano & topo ['cop'] \\
\hline palco & retumbant & tordillo \\
\hline palillo & revoltós & tormenta \\
\hline palurdo & rogar & tormentós \\
\hline pandero & ropatge & torpe \\
\hline panyo & ruedo & torpesa \\
\hline párrafo & ruido & tostorro \\
\hline párroco & ruidós & trago \\
\hline pelea & sambenet & trajo \\
\hline perro [«nom d'oprobi»] & sarro & trance \\
\hline peto & sayo & trasero \\
\hline pícaro -a & séquit & trasto [n. a. per Fabra] \\
\hline pillo & sello & tropessar \\
\hline pimentó [n. a. per Fabra] & silló & trueco [esp. trueque] \\
\hline piropo & sombra & vano \\
\hline pispar & sombrero & varilla \\
\hline pito & sombrilla & villancico \\
\hline plasso & sonido & viso \\
\hline polvo [«lo tabaco molt»] & sonrís & vulgo \\
\hline portento [també du portent] & sonrisa & xarco \\
\hline prenda & sopetó & xasco \\
\hline prendar-se & sortija & xato [n. a. per Fabra] \\
\hline pues & sublevar & xillar [els animals] \\
\hline puesto & sumba [«xasco, burla»] & xiste \\
\hline puntillo & sumbarse ["xasquejar, fér & xistós \\
\hline puntillós & burla»] & xorlito \\
\hline quarto & susto & xorro \\
\hline rama & sutano & xubasco \\
\hline ramalasso & tablado & xulada \\
\hline rana & taladrar & xulo \\
\hline rasgo & taladre & zelos \\
\hline rato & tamany & zutano \\
\hline rebato & tarea & \\
\hline recado & tarugo & \\
\hline recato & temprá -na & \\
\hline
\end{tabular}


La nòmina és molt llarga i variada, per la qual cosa provarem de fer una sistematització.

I. Formes acabades en $-o$. Una gran part són formes cultes, d'etimologia grega o llatina, entrades al català per la via de l'espanyol, si bé en alguns casos (modo, ànimo, absurdo, diàlogo, epílogo, mètodo, etc.) alguns autors consideren que són llatinismes. En aquesta llista també hi ha paraules formades amb un sufix deverbalitzador -o (abandono, desacato, giro), que hauria de correspondre en català a altres sufixos o al morfema zero. Totes aquestes formes van ser rectificades per Pompeu Fabra, unes vegades simplement suprimint la vocal final (acéfalo), altres substituint-la per $-e$ després d'un grup consonàntic (teatro, metro) o per -us (ano), i altres canviant-la per un morfema català (abandono). Aquesta és una de les aportacions més espectaculars de Fabra. Distingirem tres casos.

a) Entrades acabades en $-o$ amb definició. Per al lexicògraf, no hi ha en català altres formes que aquestes, tot i que en algun cas recull dues formes (la hispanitzant $\mathrm{amb}-o$ i la que s'ajusta a l'ús actual). En alguns casos les dues formes són definides i tenen entrades diferents (a la nostra taula les consignam totes dues en el lloc que correspongui). Altres vegades les dues formes van en una mateixa entrada separades per la conjunció y o en dues entrades consecutives però definint només una forma (en aquest cas consignam la forma no definida entre claudàtors). Si és el cas, també consignam aquí la indicació ant (antic).

Taula 4

abandono

absurdo

acéfalo

acomodo

adorno

adúltero

aerómetro

agrado

agustino -a

alacayo

alcalímetro alvéolo

amfiteatro

amianto

amparo

andrógino

ánimo

annéxo

ano

anómalo

antídoto

antropófago apóstrofo

aquaducto

arbusto

árido

arquitecto [i arquitecte]

assessino

assilo

assirio

assumpto [i assumpte]

asterisco

astrónomo 
Gabriel Bibiloni

El lèxic català del segle XIX: els hispanismes del Labèrnia

\begin{tabular}{|c|c|c|}
\hline átomo & cigarro & dissíl-labo \\
\hline autógrafo & cilindro & dissimulo \\
\hline avaro & circo & ditirambo \\
\hline ávido & circunflexo & diurno \\
\hline Baco & claustro [v. taula 5 ] & dividendo \\
\hline báculo & cloro & dominicá -a \\
\hline banderado & cloruro & dominico \\
\hline barato & cobro & ébano \\
\hline bárbaro & cocodrillo [sic] & efímero \\
\hline barómetro & cómodo & elenco \\
\hline basalto & complexo & encéfalo \\
\hline bávaro & conato & encéfalo \\
\hline beato [v. taula 5$]$ & cóncavo -a & enciso ['incís'] \\
\hline besugo & conducto & energúmeno \\
\hline bígamo & congruo & enterro \\
\hline biógrafo & connexo & Eolo \\
\hline blasfemo & cono & epiceno \\
\hline boato & contrabando & epílogo \\
\hline boro & convexo & epíteto \\
\hline Bósforo & corso & escaleno \\
\hline búfalo & cotxero & escenógrafo \\
\hline búlgaro & Cristo & escroto \\
\hline busso & croato & esófago \\
\hline busto & cronógrafo & estrado \\
\hline cabildo & crótalo & estupendo \\
\hline calígrafo & cubo & éxodo \\
\hline calorímetro & cuento & fátuo \\
\hline calvo & culto & fauno \\
\hline cándido & Dámaso & fausto \\
\hline cántabro & decágono & fecundo $-\mathrm{a}$ \\
\hline capítol [terme de rel.] & demagogo -a & fenómeno \\
\hline capritxo & derrotero [mar] & feto \\
\hline caramel-lo & desacato & feudo \\
\hline carbono & desafio o desafiu & fixo $-\mathrm{a}$ \\
\hline Carlos & desagrado & foco \\
\hline carnívoro & descontento & folleto \\
\hline cartutxo & desespero & foro \\
\hline casco & desterro & fósforo \\
\hline catastro & destino [v. taula 5$]$ & fotógrafo \\
\hline cauto & diáfano & franciscá y franciscano -a \\
\hline Cayetano & dialecto & fraterno [v. taula 5] \\
\hline cedro & diálogo & fructífero -a \\
\hline cego [v. taula 5] & diámetro & gallego \\
\hline centro [v. taula 5] & diftongo & género \\
\hline cervo & disco & geógrafo \\
\hline cetro $[$ v. taula 5$]$ & disparo & giro \\
\hline ciclo & dissenyo & globo \\
\hline
\end{tabular}




godo
golfo
grupo
guindo
guisado
habano -a
habilitado
heptágono
herbívoro
heterodoxo
hexáedro
hexágono
hexámetro
hidrófogo
hidrógeno
higrómetro
hipódromo
hipopótamo
holocausto
horóscopo
horrendo
húngaro
imbecil-lo
ímprobo
incauto -a
inciso
incómodo -a
indecoro
infecundo -a
ínfimo -a
inmundo -a
íntegro -a
intel-lecto
interino -a
intérvalo
Jacint ant y Jacinto
jubileo
laberinto
laxo -a
lento -a
lleopardo
lucro
lustro
luxo
madrilenyo -a

\begin{tabular}{|c|c|}
\hline mamífero & opaco -a \\
\hline manco -a [v. taula 5] & ópalo \\
\hline mandato & opíparo -a \\
\hline manso -a & oracle y oráculo \\
\hline manto & orfeo \\
\hline materno -a & órgano ['òrgan’] \\
\hline meditabundo & ortodoxo - a \\
\hline ménstruo & ostrogodo -a \\
\hline mestrasgo & óvalo \\
\hline metéoro & ovíparo \\
\hline método & óxido \\
\hline metro & oxígeno \\
\hline minotauro & pábulo \\
\hline missántropo & pago \\
\hline mito & palácio [v. taula 5] \\
\hline $\operatorname{mixto}-\mathrm{a}$ & paleógrafo \\
\hline modelo & pálido -a [v. taula 5] \\
\hline modo & pálio \\
\hline módulo & pantan y pantano \\
\hline monólogo & pantomimo \\
\hline monosíl-labo & paralelo \\
\hline monótono -a & paralelógramo \\
\hline mónstruo & parámetro \\
\hline múltiplo & paraninfo \\
\hline nano ['nan'] & parapeto \\
\hline nardo & párvulo \\
\hline nasareno & passo ['pas'] \\
\hline nato $-\mathrm{a}$ & pávido -a \\
\hline náufrago & peciolo \\
\hline navarro -a [v. taula 5$]$ & pedicuro \\
\hline nefando -a & pelícano \\
\hline nefasto -a & pentágono \\
\hline nímio -a & pentateuco \\
\hline noctámbulo -a & percibo [«acció de percibir»] \\
\hline nocturno -a & pérfido -a \\
\hline nul-lo -a & período \\
\hline obelisco & perplexo -a [v. taula 5] \\
\hline oblongo -a & picardo $-\mathrm{a}$ \\
\hline obsceno -a & pigallo \\
\hline óbvio -a & pio -a \\
\hline océano & plácido -a \\
\hline octáedro & plátano [arbre] \\
\hline octágono & plebeu y plebeyo -a \\
\hline octosíl-labo & plomero ['plomissol'] \\
\hline olfat y olfato [i olfacto ant] & polaco -a [v. taula 5] \\
\hline olimpo & poliedro \\
\hline omnímodo & polígamo -a \\
\hline
\end{tabular}




\begin{tabular}{|c|c|c|}
\hline polígloto -a & romanso & taquígrafo \\
\hline polígono & rombo & tarso \\
\hline polígrafo & rostro & tártaro -a \\
\hline pólipo & rublo & taumaturgo \\
\hline polisíl-labo & rudo -a & tauro \\
\hline poro & rumbo & teatino \\
\hline portent y portento & sacrílego -a & teatro \\
\hline póstumo -a & sacro -a & telégrafo \\
\hline potro [v. taula 5] & salvo $-\mathrm{a}$ & tercet ó terceto \\
\hline presbítero & salvoconducte ó & tércio \\
\hline presumpto -a & salvoconducto & termómetro \\
\hline producto & sándalo & terreno $[\mathrm{v}$. taula 5$]$ \\
\hline prófugo -a & sargento & tipógrafo \\
\hline profundo -a & sátiro & tomo \\
\hline prolixo -a & Saturno & topaci o topácio \\
\hline próspero -a & seno & tórrido $-\mathrm{a}$ \\
\hline prototipo & sério -a [v. taula 5] & trapécio \\
\hline pulcro -a & sexo & tremendo $-\mathrm{a}$ \\
\hline quadrilátero & sicómoro & tribuno \\
\hline quadro & sigil-lo & trino [adj.] \\
\hline quadrúpedo & símio -a & triptongo \\
\hline quádruplo -a & sincero $-\mathrm{a}$ & trisíl-labo \\
\hline quarteto & sínodo & triunfo \\
\hline quidrilongo & sócio & trono \\
\hline quilo ['quil'] & sólido -a & tropo \\
\hline rádio ['radi'] & soli y sólio & tubo \\
\hline ranxero & soneto & uníssono -na \\
\hline rapto & sonido [i so] & útero \\
\hline raro [v. taula 5] & sonoro & vagamundo -a \\
\hline recinto & soporífero & vago $-\mathrm{a}$ \\
\hline reflexo -a & sórdido $-\mathrm{a}$ & vampiro, vampir \\
\hline refluix ant y refluxo & sossego & vándalo \\
\hline regalo & sueco $-\mathrm{a}$ & vário -a \\
\hline régio -a & sulfuro & vermífugo \\
\hline reintegro & sumando & vértigo \\
\hline rellevo & sumo -a & visigodo $-\mathrm{a}$ \\
\hline reo & superbo [v. taula 5] & viso \\
\hline reparto & supremo -a & vistasso \\
\hline repto ['desafiament'] & sustento & voto ['execració'] \\
\hline resto & tabaco & yoduro \\
\hline retardo & taciturno $-\mathrm{a}$ & \\
\hline retiro & taco & \\
\hline retracto ['retracte'] & tacto & \\
\hline retrato & talco & \\
\hline retrógrado -a & tamarindo & \\
\hline rígido -a & tamborino & \\
\hline robo & tanto & \\
\hline
\end{tabular}


b) En alguns casos hi ha entrades amb les formes avui usuals amb remissió a una forma hispanitzant. Les primeres són considerades antigues per Labèrnia ( $\mathrm{i}$ a voltes es marca aquesta circumstància) i les segones, les normals i usuals.

\section{Taula 5}

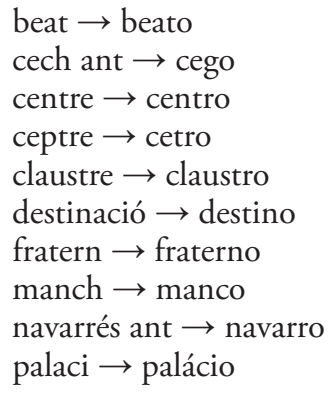

$$
\begin{aligned}
& \text { palau } \rightarrow \text { palácio } \\
& \text { pálit } \rightarrow \text { pálido } \\
& \text { perpleix } \rightarrow \text { perplexo } \\
& \text { polonés } \rightarrow \text { polaco } \\
& \text { poltro } \rightarrow \text { potro } \\
& \text { rar ant } \rightarrow \text { raro } \\
& \text { seriós ant } \rightarrow \text { sério } \\
& \text { superbe } \rightarrow \text { superbo } \\
& \text { terreny ant } \rightarrow \text { terreno }
\end{aligned}
$$

c) Entrades acabades en $-o$ que remeten a una forma considerada millor (generalment, però no sempre, no interferida).

\section{Taula 6}

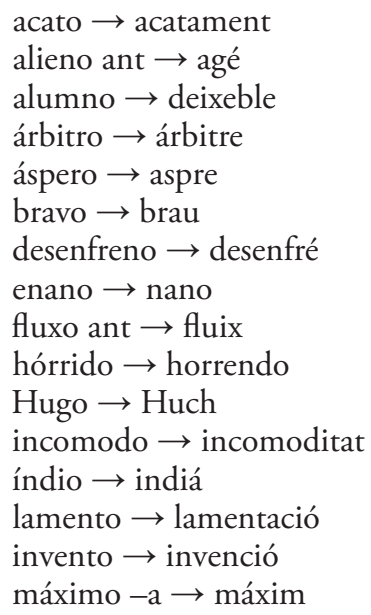

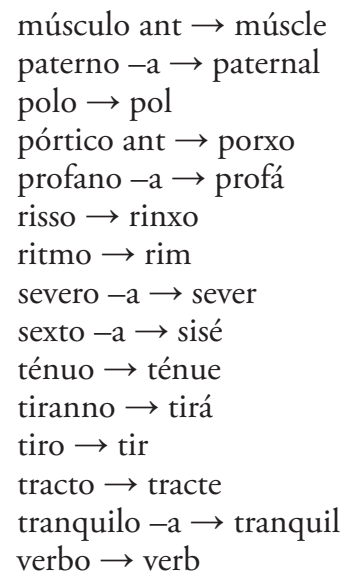


Taula 8

ambíguo -a

árduo -a

conspícuo -a

contíguo -a

contínuo -a

exíguo -a

indivíduo

ingénuo -a

mútuo -a

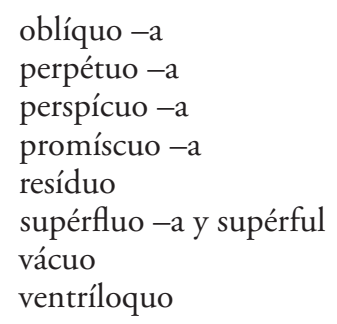

5. Paraules amb la terminació -cul o - gul corresponents a les llatines -culus o - gulus. Aquí apareixen algunes formes amb la terminació - cle, que Fabra generalitzaria (amb alguna excepció, com òscul i ridícul), si bé predominen les formes hispanitzades acabades en -o o en -cull -gul. Hi ha angle, amb la marca ant, que remet a àngul. En el diccionari apareixen les formes cercle, cerco i cércol, totes amb el significat de 'cèrcol'.

\section{Taula 9}

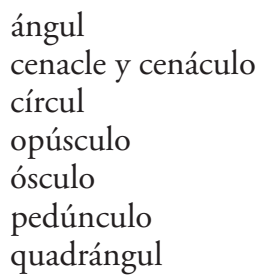

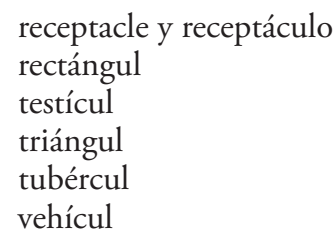

6. Paraules amb la terminació -logo, -loga i -loch, -loga. A la taula 4 ja hem vist els casos de diálogo, epílogo i monólogo, que només tenen aquestes variants. En canvi, en el diccionari apareix análoch-ga i homólech-ga, segurament amb tractament diferent dels tres primers pel fet de ser adjectius. I també amb tractament diferent entre tots dos.

7. Paraules amb la terminació - sis corresponents a ètims grecollatins en -sis. La reducció a -si va ser obra de Fabra. Labèrnia registra apoteosa, hipotesa i hipotipossa, formes franceses recollides abans per Lacavalleria. 
Gabriel BibiLONI

El lèxic català del segle XIX: els hispanismes del Labèrnia

Taula Io

análisis
antítesis
apocalipsis
apódosis
apófasis
apófissis
apoteosa y apoteosis
crisis
dosis
énfasis

hipóstasis

hipotesa y hipotésis

hipotipossa y hipotipossis

oasis

paréntesis

perífrasis

sinopsis

sintaxis

síntesis

8. Formes acabades amb el sufix deverbalitzador $-e$. Com se sap, aquest és un sufix molt productiu en espanyol i els hispanismes que el porten en el català vulgar són molts. En el Labèrnia, però, només es registren acorde, deleyte i passe, amb definició. També hi apareix escape amb remissió a escapament. Curiosament apareixen els deverbals ataco (esp. ataque), remato (esp. remate), saco (esp. saque) i truco (esp. trueque), a més de aguant.

9. Formes acabades amb els sufixos - eo o - eig. També és un sufix molt productiu en espanyol, i en català actual es troben nombrosos esquivalents amb la forma -eig (bombeig, sondeig, etc.). En el Labèrnia hi ha fondeo i rodeo, que remet a rodeig. També hi ha tanteig, igual que el verb tantejar.

Io. Formes acabades amb el sufix -ero. Hi trobam agafadero, amarradero, atracadero, babadero (baverall), despenyadero (i despenyador), embarcadero, encalladero i fondejadero.

II. Paraules amb la terminació -ice corresponent a la terminació llatina-ex-icem. Només hi hem trobat ápice i vértice. Fabra hi imposà la forma nominativa llatina, contra la forma acusativa espanyola.

I2. Altres paraules mediatitzades formalment per l'espanyol. Són formes que presenten anomalies pel que fa al seguiment de les regles de la gramàtica històrica catalana o presenten estructures morfològiques estranyes al sistema de derivació en català. 


\section{Taula II}

abedull
acaudalar
acert
acertar
aclaració
ademés
adivinar
aduana
afamarse [fer-se famós]
aficionar
aficionat
agé
agotar
almirall y almirant
agravació
agravador
agravant
agravar
agravi
agraviar
aleació
amargura
angústia
antorxa
apariéncia
apercibir
aquartelar
ariete
atalaya
atemorisar
ateniense
atesorar
atmósfera
atormentar
auséncia
ausent
blancura
cámara [del rei]
$\quad$ f cambra [sala]
catorzau
caudal
caudalós
celador
celda
ceremónia
and

cisne

concebir y concébrer

cónsul

culebra

cursillo

curva $[$ nom]

deleyte

deleytar

desagravi

desagraviar

desahogar (se)

desparercibit y

desapercebut -da

desembols

desempenyar

desnudesa

despreci

despreciar

desprendiment

desvanéixer

desvanescut

diapasson

difundir

eclipse

enagenar

enfervorisar

engullir

ensaig

envenenar

epígrafe

escabullirse

estirpe

fleuma

fleumátic

gasseós

grande [títol]

héroe

horisont

iman

infiel

infundir

ingeni

inglés

isla

isleta islot

lasaret

manguito

matxete

mejicá [i Méjico]

miope

munícipe

necedat

óbice

octau [vuitena part]

olvidar

olvit

omitir

ondejar

orquesta

panteon

parque

pendó

percibir

picadillo ["guisado de carn trinxada»]

picotilla o pacotilla

pienso

placenter

platillo

quadernillo

quartel

quilat

rebelde

recaudar

recomendació [«acció de recomanar»]

régimen

remanent

repudi

rigorós ó rigurós -a

rigurosament

sangrar

sangria

satél-lite

sede

senzillés y senzillesa

siesta

sigle

soberá -na 
Gabriel Bibiloni

El lèxic català del segle XIX: els hispanismes del Labèrnia

$\begin{array}{lll}\text { sublevar } & \text { telégrama } & \text { vascuence } \\ \text { sublime } & \text { templari } & \text { veneno } \\ \text { sumergir } & \text { tiburó } & \text { víbora } \\ \text { sutil } & \text { transmitir } & \text { villania } \\ \text { sutilesa } & \text { trasladar } & \text { volumen } \\ \text { talisman } & \text { trégua } & \neq \text { volum ['embalum'] }\end{array}$

També hi ha un conjunt d'entrades amb forma generalment hispanitzada que remeten a formes genuïnes.

Taula I2
aclarar $\rightarrow$ aclarir
canciller $\rightarrow$ canceller
afan $\rightarrow$ afany
casi $\rightarrow$ quasi
árabe $\rightarrow$ arábich
cero $\rightarrow$ zero
azafata ant $\rightarrow$ safata ['criada']
comerci $\rightarrow$ comerç
calis $\rightarrow$ cálzer
mármol $\rightarrow$ marbre

I entrades amb les formes considerades avui correctes que remeten a formes hispanitzants. Les primeres devien ser considerades antiquades per l'autor, incloent-hi bigot.

Taula I3

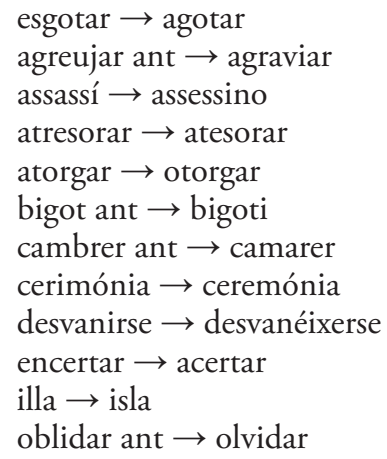

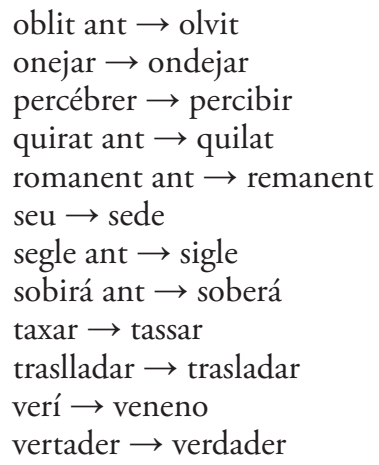




\section{CONCLUSIONS}

En el Labèrnia els hispanismes de forma constitueixen al voltant de dos terços del total, mentre que l'altre terç correspon a hispanismes amb un lexema netament espanyol. Per altres recerques nostres en curs sabem que els hispanismes lexemàtics que foren exclosos de la normativa per Fabra són una part relativament petita dels hispanismes totals de la llengua, la major part dels quals no foren depurats, sigui per desconeixement de la seva condició d'hispanismes, sigui per la inexistència d'una paraula alternativa que pogués substituir-los o sigui perquè, no presentant signes de «malformació», eren més assumibles pel projecte codificador iniciat al començament del segle xx. Per contra, si bé hi ha en els diccionaris de referència actuals bastants mots que acusen la mediatització formal de la llengua espanyola (Bibiloni 20I2), la major part foren esmenats pel geni de Pompeu Fabra, amb el suport de l'entorn modernista i noucentista que amb ell sintonitzava. I aquí radica l'excel-lència i el caràcter revolucionari de la seva obra. La part més visible d'aquesta acció és la correcció de les paraules acabades en -o (bàrbaro, cubo, cràneo, fixo, indivíduo, periodo, tomo, vàndalo, etc.), un contingent lèxic enormement extens que havia entrat per la via de l'espanyol i que en la llengua parlada i escrita només es manifestava amb aquella forma. Avui un parlant de cultura mitjana pot restar molt sorprès de veure que en el millor diccionari català del segle XIX només hi ha aduiltero, agustino, arbusto, mandato, mito, òbvio, òxido, pòstumo, producto o sincero, i que paraules com palau, assassí, illa o oblidar són considerades antiquades i relegables davant palàcio, assessino, isla o olvidar. L'anàlisi del diccionari Labèrnia ens fa veure el contrast colpidor que hi ha entre la llengua desnortada del XIX i —malgrat totes les mancances— la llengua elaborada, amb la guia de la genuïnitat, dels segles Xx i XxI.

Gabriel Bibiloni

Universitat de les Illes Balears

gabriel.bibiloni@uib.cat

ORCID 0000-0002-5152-I485

Caplletra 63 (Tardor, 2017), pp. 55-78 
GABRIEL BibiLONI

El lèxic català del segle XIX: els hispanismes del Labèrnia

\section{REFERÈNCIES BIBLIOGRÀFIQUES}

Bibiloni, Gabriel (2012) Amb bones paraules, Palma, Lleonard Muntaner.

Bofarull, Antoni de (I864) Estudios, sistema gramatical y crestomatía de la lengua catalana, Barcelona.

Bofarull, Antoni de \& Adolf Blanch (i867) Gramática de la lengua catalana, Barcelona, Espasa Hermanos.

Colón, Germà \& Amadeu Soberanas (1986) Panorama de la lexicografia catalana, Barcelona, Enciclopèdia Catalana.

Comas, Antoni (I972) Història de la literatura catalana, vol. IV, segle XviII, Barcelona, Ariel.

Font, Antoni (1637) Fonts verborum et phrasium, Barcelona [Diccionari llatí-català].

LaCaVAlleria, Joan (I696) Gazophylacium catalano-latinum, Barcelona.

Miret y SAns, Joaquim (I917-1920) «Dos siglos de vida académica», Boletín de la Academia de Buenas Letras de Barcelona, IX.

Montalat Buscató, Pere (2015) «Contribució a l'estudi del lèxic del Gazophylacium catalano-latinum», Estudis Romànics, 37, pp. 373-384.

Pou, Onofre (I575) Thesaurus puerilis, València.

Ros, Carlos (I764) Diccionario valenciano-castellano, València.

Segarra, Mila (1985) Història de la normativa catalana, Barcelona, Enciclopèdia Catalana.

SolÀ, Joan (1977) Del català incorrecte al català correcte, Barcelona, Edicions 62.

Torra, Pere (I640) Dictionarium seu thesaures catalano-latinum verborum ac phrasium, Barcelona.

Ullastre, Josep (I743) Gramàtica catalana embellida ab dos ortografies, Barcelona.

VENY, Joan (20I6) «Lexicografia comparativa del segle XVIII: els diccionaris de Font, Torra i Lacavalleria», dins M. À. Pradilla (ed.), Miscel-lània d'homenatge a Joan Martí $i$ Castell, Tarragona, Universitat Rovira i Virgili, pp. I77-I89. 